Varieties of (Scientific) Creativity

Dean Keith Simonton

Varieties of (Scientific) Creativity

A Hierarchical Model of Domain-Specific Disposition, Development, and Achievement

Dean Keith Simonton

University of California, Davis

Address correspondence to Dean Keith Simonton, Department of Psychology, 1 Shields Avenue, University of California, Davis, CA 95616-8686; e-mail dksimonton@ucdavis.edu. 
ABSTRACT—Prior research supports the inference that scientific disciplines can be ordered into a hierarchy ranging from the "hard" natural sciences to the "soft" social sciences. This ordering corresponds with such objective criteria as disciplinary consensus, knowledge obsolescence rate, anticipation frequency, theories-to-laws ratio, lecture disfluency, and age at recognition. It is then argued that this hierarchy can be extrapolated to encompass the humanities and arts and interpolated within specific domains to accommodate contrasts in subdomains (e.g., revolutionary versus normal science). This expanded and more finely differentiated hierarchy is then shown to have a partial psychological basis in terms of dispositional traits (e.g., psychopathology) and developmental experiences (e.g., family background). This demonstration then leads to three hypotheses about how a creator's domain-specific impact depends on his or her disposition and development: the domain-progressive, domain-typical, and domainregressive creator hypotheses. Studies published thus far lend the most support to the domainregressive creator hypothesis. In particular, major contributors to a domain are more likely to have dispositional traits and developmental experiences most similar to those that prevail in a domain lower in the disciplinary hierarchy. However, some complications to this generalization suggest the need for more research on the proposed hierarchical model. 
A recurrent issue in the study of creativity is whether the phenomenon is domain specific or domain general (e.g., Simonton, 2007; Sternberg, 2005). Can psychologists plausibly speak of a generic creative process that transcends the particular problem-solving tasks of any given domain? Is the creative thought of an Albert Einstein comparable with that of a Pablo Picasso? Or must we draw the contrary conclusion that there is no such thing as a "one-size-fits-all" creative process? Is the thinking that produced the general theory of relativity fundamentally distinct from that which created a painting like Guernica? And do the dissimilarities in cognitive processes transcend the superficial contrast between solving equations and mixing paints? Would brain scans of Einstein and Picasso look fundamentally different when each came up with a breakthrough insight while lost in thought?

Although this question is most often framed in terms of the creative process, it also can also be cast in term of the creative person. Is the disposition of a creative scientist distinguishable from that of the creative artist? Would Einstein and Picasso have received radically different scores on standard personality tests? And if artists and scientists differ in disposition, wouldn't we also expect them to have contrasting developmental antecedents? After all, to some extent, dispositional traits are a function of specific environmental experiences. Hence, can creators who contribute to different domains be distinguished according to family background, educational experiences, and other critical influences? Could Einstein be separated from Picasso just by reading their respective childhood and adolescent biographies? Finally, would this dispositional and developmental divergence between scientific and artistic creativity correspond in some way to domain contrasts in the creative process? Does it require a unique set of dispositional traits and developmental events to engage in the processes that support scientific creativity rather than those that support artistic creativity? 
Fortunately, a large body of research has been devoted to discerning the dispositional and developmental correlates of various kinds of creativity (e.g., Feist, 1998, 2006; Simonton, 1987). In fact, such studies date back to Cox (1926), Raskin (1936), Roe (1953), and Terman (1954). So there is no dearth of empirical findings addressing this question. If anything, these investigations have produced too many results. Not only can we distinguish between scientific and artistic creativity, but we can also discern dispositional and developmental contrasts among diverse forms of either science or art. A creative physicist is not the same as a creative psychologist, nor is a novelist the same as a poet (e.g., Ludwig, 1998). Even two physicists may psychologically differ in ways that tells us something about the nature of their scientific creativity (e.g., Roe, 1953). Hence, what we currently possess is a chaos of miscellaneous puzzle pieces that we hope can be eventually placed together to form a single coherent picture of how the creative process and person might systematically vary across different domains of creativity.

It is the purpose of this article to argue for one possible dimension that might successfully coordinate these disconnected data points. This argument begins with a discussion of whether the major scientific domains can be objectively arrayed in a hierarchy that represents differences in how practitioners create science. After reviewing empirical evidence for this hierarchy, I suggest that the same core principles underlying this arrangement can also be extrapolated beyond science to include the arts and humanities and interpolated within specific sciences to handle important within-discipline forms of creative contribution. Later, I show that dispositional and developmental factors that differentiate creators operating in various domains closely parallel a domain's placement along this dimension. This demonstration then leads to a discussion of whether a creator's success or impact within a given domain corresponds to whether his or her 
dispositional traits and developmental experiences are typical of their chosen domain rather than a domain higher or lower in the supposed hierarchy.

\section{DISCIPLINARY HIERARCHY}

Auguste Comte (1839-1842/1855), the French positivist philosopher, proposed that scientific disciplines could be ordered into a hierarchical arrangement (viz., astronomy, physics, chemistry, biology, and sociology). This concept has echoes in such contemporary distinctions as “exact” versus "nonexact" sciences, "hard” versus "soft” sciences, "paradigmatic" versus "preparadigmatic" sciences, and perhaps even "natural" versus "human" sciences. The idea is also implicit in the relative status of the physical, biological, and social sciences, and it may even play a role in the comparative prestige of the sciences, the humanities, and the arts (as judged, say, by the amount of grant money made available or the earnings of college graduates in each of the three areas).

More important, a recent investigation demonstrated that the suggested hierarchy has empirical justification (Simonton, 2004; see also Simonton, 2002). In particular, the four test domains of physics, chemistry, psychology, and sociology were assessed on the following seven indicators of scientific status: (a) citation concentration to specific research articles (Cole, 1983), (b) early impact rate for scientists under 35 (Cole, 1983), (c) peer evaluation consensus (Cole, 1983), (d) obsolescence rate (McDowell, 1982), (e) graph prominence (Cleveland, 1984), (f) consultation rate (a negative indicator; Suls \& Fletcher, 1983), and (g) the theories-to-laws ratio (also a negative indicator; Roeckelein, 1997).

The first three measures concern the extent to which scientists in a given discipline agree on what constitutes a contribution to the domain. Scientists operating in domains higher in the hierarchy should be more inclined to cite the same articles, to more quickly recognize the 
outstanding work of their younger colleagues, and to agree on who among their colleagues are doing the best work (Cole, 1983). The obsolescence rate is the expected cost in publication output as a result of interrupting a career for 1 complete year and thus gauges the rate at which domain-specific expertise becomes out of date (McDowell, 1982). The indicator of graph prominence recognizes the fact that the more rigorous sciences tend to prefer visual representations of data over tabular presentations of statistics (Cleveland, 1984; Smith, Best, Stubbs, Johnston, \& Archibald, 2000). The consultation rate, which is based on the acknowledgment sections of published articles, reflects the degree to which the authors' sought the advice of their colleagues before submitting their work for editorial review. It is thus a measure of disciplinary uncertainty about the merits of one's work (based on social comparison theory; Suls \& Fletcher, 1983). Finally, the theories-to-laws ratio presumes that higher status disciplines boast an intensive inventory of confirmed laws whereas lower status disciplines have a much greater collection of speculative theories (Roeckelein, 1997; see also Roeckelein, 1996).

Not only did the above seven measures correlate very highly, but also a principal components analysis confirmed that all seven measures loaded on a single factor identifying a discipline's place in the hierarchy (loadings ranged from .86 to .99). Furthermore, factor scores on this single dimension $(\alpha=.96)$ were validated by calculating their correlations with other measures that also have some bearing on a discipline's scientific status but that could not be used in the main analysis because the scores were not available for all four test domains (Simonton, 2004). These were (a) citation immediacy, a measure of whether citations concentrate on the most recent publications (i.e., with rapid decay rates as a function of time; Cole, 1983); (b) anticipation frequency, a measure of the degree to which scientists had their research anticipated by other scientists working in the same discipline (Hagstrom, 1974); (c) rated disciplinary 
hardness, a subjective indicator of whether a discipline is "hard" or "soft" according to faculty and student respondents (Smith et al., 2000); (d) the average age at receiving the Nobel prize for distinct disciplines (a negative indicator operating as the inverse of the early impact rate; Stephan \& Levin, 1993; see also Manniche \& Falk, 1957); and (e) lecture disfluency - the rate of filled pauses ("uh," "er," and "um") during classroom lectures for undergraduate courses (a negative indicator suggesting some imprecision in basic disciplinary concepts; Schachter, Christianfeld, Ravina, \& Bilous, 1991). The correlations were uniformly high and all were in the predicted direction ( $r$ s between .60 and .97 , with a median of .88). Although a given discipline might be out of order with respect to a given criterion, these exceptions are too few and too small to undermine the overall statistical consistency.

Hence, it was established that scientific disciplines could be objectively placed in a hierarchical configuration. To provide a concrete illustration, Figure 1 shows the resulting arrangement of the disciplines of physics, chemistry, biology, psychology, and sociology (Simonton, 2004). It is not only the case that the physical sciences score higher than the biological sciences, which score higher than the social sciences, but it is also evident that physics and chemistry are a bit removed from biology and that psychology is somewhat closer to biology than to sociology. This clustering likely captures the views of most scientists about the relative scientific status of these five disciplines (but see Hedges, 1987; Rosenthal, 1990, for more optimistic views of psychology's status).

I must now elaborate this hierarchy in two directions: extrapolation and interpolation.

\section{Extrapolation}

Although the above investigation only examined scientific disciplines from physics and chemistry to psychology and sociology, it should be clear that many of the same evaluative 
criteria apply to scholarship the humanities. Indeed, two of the investigations on which the analysis was based included measurements that extended beyond the sciences proper (Simonton, 2004).

First, the obsolescence rate was determined for the disciplines of history and English, as well as the disciplines of physics, chemistry, biology, psychology, and sociology (McDowell, 1982). Significantly, knowledge gets out of date far more slowly in the two humanities relative to the five sciences. History and English professors can take time off from research for other duties — such as assuming administrative positions — with less detriment to their productivity than holds for a professor of a scientific discipline, especially one in the natural sciences. Strikingly, physics is as far above the mean in the obsolescence rate as English is below the mean. A scientist in high-energy physics has to do a lot more to keep up with the leading edge in his or her discipline than does a scholar in Shakespeare studies.

Second, the inquiry into lecture disfluency also scrutinized the humanities along with the sciences and the investigators found that the disfluency exhibited in political science, art history, and English exceeds that witnessed in sociology and psychology (Schachter et al., 1991). It is interesting to note that the discipline of philosophy, which places a premium on conceptual and logical precision, scored somewhere between psychology and chemistry on this measure. In that respect, philosophers are more similar to scientists than to scholars in the humanities.

Besides extrapolating the hierarchy into the main humanistic disciplines, we may even extend it farther into the arts, albeit many of the indicators would have to acquire broader operational definitions. Granting this extension, the psychological factors that differentiate the "hard" from the "soft" sciences might also distinguish the sciences from the arts. Better yet, the same discriminating variables might also separate different kinds of arts (e.g., formal vs. 
expressive, classical vs. romantic, Apollonian vs. Dionysian, linear vs. painterly). Later in this article, I will present evidence that this extrapolation beyond the sciences and humanities has empirical justification.

\section{Interpolation}

To be more accurate, the hierarchical placement of sciences shown in Figure 1 should incorporate error bars. Each science is placed according to its center of gravity or central tendency, but it is incorrect to assume that that all practitioners operate at that mean level. It is probably the case that there is sufficient variation within each discipline that the distributions overlap. It may even be possible that some physicists are "softer" than some psychologists (Cole, 1983). A portion of this variation may be attributed to within-discipline individual differences, a possibility that I will treat in later in this article. Right now, I will discuss between-subdiscipline group differences, for it should be evident that some subdisciplines of a given science will have higher standing relative to the average for that science and that other subdisciplines will have a lower standing.

This variation can be illustrated using a study of the long-term impact of 54 eminent psychologists (Simonton, 2000). The psychologists had been previously assessed on their theoretical and methodological orientation (Coan, 1968, 1979). That is, they were scored with regard to whether their psychology was objectivistic or subjectivistic, quantitative or qualitative, elementaristic or holistic, impersonal or personal, static or dynamic, and exogenist or endogenist. A factor analysis then showed that these six measures formed a single factor that distinguished psychologists who had a more "soft," "tender-minded," or "human-science" orientation from those who had a more "hard," "tough-minded," or "natural-science" orientation (Simonton, 2000). The psychologist's long-term citation rate was then shown to be a U-shaped function of 
placement along this general factor: Psychologists representing the extremes are more influential than those representing more moderate compromises in the middle of the distribution.

The U-curve suggests that there are really two psychologies, with the discipline's most eminent psychologists occupying different locations in the hierarchy shown in Figure 1 (see also see also Kimble, 1984). B.F. Skinner and Carl Rogers never resolved their famous 1962 debate because each represented a distinct domain of psychological creativity. It is also telling that the degree of disciplinary consensus seen in Skinner's radical behaviorism, as gauged by articles published in the Journal for the Experimental Analysis of Behavior, is in the same league as research that appears in the hard sciences (Cole, 1983).

Presumably most scientific disciplines become increasingly scientific over historical time (for review, see Simonton, 2002). However, circumstances may arise in which a given science might regress toward a lower spot on the hierarchical dimension. This possibility can be inferred from Kuhn's (1970) theory of scientific revolutions (cf. Gholson \& Barker, 1985). Although Kuhn made an emphatic distinction between paradigmatic and nonparadigmatic disciplines - the latter clearly having a higher placement in the hierarchy—sometimes research in an established paradigm starts to generate results inconsistent with paradigmatic expectations. As these anomalies accumulate, the science enters a crisis stage in which the disciplinary consensus and codification breaks down. In effect, the science retreats down the hierarchy. But most frequently this crisis is resolved by the advent of a new paradigm that replaces the old one, enabling the discipline to recover its previous elevated status. The failures of Newtonian mechanics and Maxwellian electrodynamics were saved by the advent of relativity and quantum theories. Hence, Kuhn (1970) argued that paradigmatic sciences actually have two kinds of practitioners. On the one hand are the scientists who perform "normal science" that is largely 
dictated and constrained by the accepted paradigm. Such scientists are engaged in mere "puzzlesolving" research (i.e., working out the logical and empirical details of various paradigmatic implications). On the other hand are the scientists who practice "revolutionary science" that is committed to replacing the old with the new. It seems reasonable to suggest that this distinction closely follows that underlying a domain's placement in the disciplinary hierarchy. In essence, revolutionary scientists during a paradigmatic crisis operate lower down in the hierarchy than do normal scientists operating after a paradigm has been fully established.

\section{PSYCHOLOGICAL CORRELATES}

Given the foregoing considerations, we can now ask whether the described differences have a psychological basis. Can we identify variables that predict a creative person's preferences regarding such contrasts as objectivity versus subjectivity, consensus versus individuality, exactness versus vagueness, constraint versus freedom, logic versus intuition, and any other dimension that might underlie the hierarchical placement of their chosen domain of achievement? The accumulated research answers in the affirmative. The type of creativity displayed by an individual is partially contingent on both dispositional and developmental factors.

\section{Dispositional Traits}

The best place to begin is the provocative work done by Ludwig $(1992,1995)$ on domain contrasts in the incidence and severity of psychopathology. Particularly important is his 1998 paper on how psychopathology varies across creative domains - a paper appropriately titled "Method and Madness in the Arts and Sciences." Ludwig argued that "persons in professions that require more logical, objective, and formal forms of expression tend be more emotionally stable than those in professions that require more intuitive, subjective, and emotive forms" (p. 
93). This argument was then confirmed by collecting extensive data on the lives of highly eminent scientists and artists. In addition, this empirical confirmation displayed the fractal pattern of "self-similarity." Specifically, Ludwig observed that this fractal pattern was found at four consecutive levels of "magnification":

Level 1: Scientists have lower lifetime rates of mental illness than do artists;

Level 2: In the sciences, natural scientists have lower rates than do social scientists, and in the arts, creators in the formal arts (e.g., architecture) have lower rates than those in the performing arts (e.g., music and dance) who in their turn have lower rates than those in the expressive arts (e.g., literature and the visual arts);

Level 3: Within a specific expressive art like literature, nonfiction writers display lower rates than do fiction writers who in their turn have lower rates than do poets; and

Level 4: Within any given artistic specialty (e.g., painting, sculpture, and photography), those who create in a formal style will exhibit lower rates than those creating in a symbolic style, and the latter exhibit yet lower rates than those creating in an emotive style. So of all varieties of creativity, poets writing in a highly emotionally expressive style should have the highest propensity for pathology.

Hence, Ludwig has established that the proposed disciplinary hierarchy corresponds to the creator's inclination toward psychopathology. Especially crucial is the contrast between the sciences and the arts and, within sciences, the contrast between the natural and social sciences.

Ludwig (1998) was not the only investigator to point out that scientific creators are less disposed to mental illness than are artistic creators. Raskin (1936) made the observation when she compared eminent scientists with eminent writers, a finding replicated by Post (1994) over a half century later: Among scientists, psychopathology was severe in $18 \%$, marked in $27 \%$, mild 
in $24 \%$, and absent in $31 \%$, but among writers, psychopathology was severe in $38 \%$, marked in $19 \%$, mild in $29 \%$, and absent in only $15 \%$. At the same time, other researchers have shown how this fractal pattern extends to the various artistic domains. As an example, Jamison's (1989) study of eminent writers indicated that the poets and novelists were far more prone to affective disorders than are biographers who most probably pursue a more logical, objective, and formal kind of creativity.

Because psychopathology is less prominent among scientists, it is less easy to tease out the exact same regularity among the sciences. Nevertheless, research does indicate that the natural sciences can be distinguished from the social sciences according to dispositional traits that have some apparent affinity with the same relationship. For instance, Chambers (1964) found that creative chemists were more likely to score lower than creative psychologists on Factor M of the 16 Personality Factors (see also Cattell \& Drevdahl, 1955). This means that psychologists are more bohemian, introverted, unconventional, imaginative, and creative in thought and behavior. Likewise, in Roe's (1953) study of 64 eminent scientists, the physical scientists (physicists and chemists) proved to be more factual, less emotional, and less rebellious than the social scientists (psychologists and anthropologists) on the Thematic Apperception Test. Taken together, these studies imply that the social scientists have dispositions somewhere between artists and natural scientists on the extrapolated hierarchy.

Finally, let me offer instances of dispositional factors that associate with contrasts within a scientific domain. I want to select psychology because I have already noted that there are really at least two psychologies that are probably located at distinct positions on the basic hierarchy (cf. Cronbach, 1957). Johnson, Germer, Efran, and Overton (1988) examined the dispositional differences between mechanistic and organismic behavioral scientists, the former emulating the 
natural-science orientation and the latter the human-science orientation. Mechanistic behavioral scientists were found to be more orderly, stable, conventional, conforming, objective, realistic, interpersonally passive, dependent, and reactive, whereas the organismic behavioral scientists were shown to be more fluid, changing, creative, nonconforming, participative, imaginative, active, purposive, autonomous, individualistic, and environmentally integrated.

On a far more limited scale regarding the number of variables investigated was Suedfeld's (1985) content analysis of addresses delivered by presidents of the American Psychological Association. The speeches were scored on integrative complexity: a measure of how many divergent perspectives a person can take into consideration and whether the person can integrate these perspectives into a coherent viewpoint. Those APA presidents who were human-science oriented demonstrated higher levels of integrative complexity than did those who were natural-science oriented.

To sum up, we have ample reason for concluding that the hierarchical arrangement of creative disciplines and their subdisciplines has a dispositional basis. This conclusion receives reinforcement in the next section.

\section{Developmental Experiences}

The empirical literature makes it manifest that the family backgrounds of creators somewhat parallel the domain of creative achievement. This correspondence is apparent in those creators who managed to receive the Nobel Prize (Berry, 1981). If we focus on the awards in the creative domains of physics, chemistry, and literature - the "physiology or medicine" prize is far too heterogeneous with respect to the disciplines covered - then we discover that placement along the hierarchy agrees with two powerful familial experiences. First, where $28 \%$ of the physics laureates had fathers who were academic professionals, this percentage lowers to $17 \%$ 
for chemistry, and a mere $6 \%$ for literature. Second, where only $2 \%$ of the physicists lost their father during their minority years, such parental loss increased to $11 \%$ for the chemists and $17 \%$ for the creative writers. Broadly, domains high in the hierarchy have practitioners who came from conventional and stable homes, whereas those active in domains low in the hierarchy are more likely to come from unconventional or unstable home environments. The contrast between the physicists and the writers is especially striking. Whereas $30 \%$ of the literature laureates "lost at least one parent through death or desertion or experienced the father's bankruptcy or impoverishment," "the physicists ... seem to have remarkably uneventful lives" (p. 387; see also Raskin, 1936).

According to Schaefer and Anastasi's (1968) research, a comparable contrast appears in the home environments of creative adolescents. They specifically contrasted the backgrounds of scientifically and artistically talented teenagers. The former were more likely come from stable homes in which their parents pursued conventional interests and hobbies, whereas the latter were more likely to grow up in unconventional homes that displayed conspicuous diversity with respect to geographic origins (e.g., foreign born), economic mobility, and extensive travels both in the United States and abroad. In a nutshell, the home environments of the scientifically gifted were closer to "normal," whereas those of the artistically gifted were decidedly more divergent from the normal—more unusual, varied, and unstable.

A data analysis of eminent 20th-century personalities also obtained corroborative results (Simonton, 1986). For instance, creative writers tended to come from unhappy home environments, whereas better home conditions produced scientists and philosophers. This investigation underlined the role played by education as well. Eminent scientists tend to have the most formal education, whereas artists and performers have the least, with poets the least likely 
to have any special school experiences. Raskin (1936) also identified an education gap separating famous scientists and writers. There is also reason to believe that eminent scientists have fewer and more homogeneous role models and mentors relative to eminent artists (Simonton, 1984, 1992b). Eminent psychologists are closer to scientists than to artists in this respect (Simonton, 1992a). Last but not least, artistic creators may be somewhat more likely to appear in unstable and heterogeneous sociocultural systems than is the case for scientific creators (Simonton, 1975, 1997). Sociocultural homogeneity and stability, by comparison, are more supportive of scientific creators (see also de Candolle, 1873).

Unfortunately, developmental studies of differences among scientific disciplines are relatively rare. Yet what little work has been done indicates a pattern consistent with what is seen in the science-versus-art comparisons. For example, creative psychologists tend to have a more rebellious relationship with their parents than do creative chemists (Chambers, 1964; see also Roe, 1953). Tense family relationships even seem to carry over into adulthood: Among 64 eminent scientists, $41 \%$ of the social scientists experienced divorce, in comparison with $15 \%$ of the biologists and only 5\% of the physical scientists (Roe, 1953; see also Post, 1994). Finally, when researchers examined a different developmental condition, they found that scientists from distinct disciplines often displayed early hobbies consistent with their disciplinary choices. In Roe's (1953) study of 64 eminent scientists, the physicists often showed an early interest in mechanical and electronic gadgets, whereas the social scientists most commonly exhibited an early fascination with literature and the classics. The latter were also far more likely to have once had aspirations to pursue literary careers. This inclination obviously puts the social scientists somewhere between the arts and the natural sciences in the extended disciplinary hierarchy. 
The deficiency in comparisons across scientific disciplines is compensated by extensive research on within-domain differences in developmental experiences. Of special interest is the empirical research on birth order. Many studies have shown a firstborn advantage in terms of educational and occupational achievement (Altus, 1966; Schachter, 1963). This general finding then has as a special case the recurrent result indicating that firstborns are more likely to become eminent scientists (Eiduson, 1962; Galton, 1874; Roe, 1953; Simonton, 2008a; Terry, 1989). Yet it is also true that literary creators may have higher odds of being laterborns (Bliss, 1970). Even so, composers of classical music may be more prone to be firstborns (Schubert, Wagner, \& Schubert, 1977). These seemingly contradictory results make sense if we assume that creators active in domains that are more logical, objective, conventional, and formal tend to be firstborns, whereas those who create in domains that are more intuitive, subjective, individualistic, and emotional tend to be laterborns. For this reason classical composers, who can be considered mathematicians of sound, are grouped with the creative scientists rather than with the creative writers - the poets and novelists who are far less logical, objective, conventional, and formal. According to Sulloway (1996), these contrasts across domains can be interpolated within domains as well. More specifically, he has provided theoretical and empirical evidence that revolutionary scientists have a higher likelihood of being laterborns. Given Kuhn's (1970) assertion that revolutionary and normal science fluctuate back and forth during the history of any science, this would imply that the relative frequency of various ordinal positions should change as well. There are indeed circumstances in which Nobel prizes in science are more likely bestowed on laterborns rather than firstborns (Clark \& Rice, 1982).

Of course, there are exceptions to this tendency, but it is to Sulloway's credit that he has also identified some of the moderating factors that either intensify or undermine the laterborn 
inclination to rebel. The most critical factors are pronounced parent-offspring conflict, age spacing of the siblings, early parental loss and surrogate parenting, gender and race, and any innate disposition toward shyness. Some of these same factors are also those that are associated with domains lower in the hierarchy (viz. pronounced parent-offspring conflict and early parental loss). So, in a sense, revolutionary scientists regress toward less logical, objective, conventional, and formal modes of creative thought. This regression corresponds with the discipline's own descent down the hierarchy as a consequence of the accumulation of paradigmdefying anomalies.

\section{INDIVIDUAL DISCIPLINARY IMPACT}

Thus far, I have provided some evidence that the disciplinary hierarchy has a partial psychological foundation. Those who contribute to a given domain have dispositional traits and developmental experiences that closely parallel their domain's placement in the hierarchical configuration. These correlates even appear to explain intradomain variation, such as the difference between revolutionary and normal scientists. But now I wish to deal with a related issue: Do individual differences on the same dispositional and developmental variables also predict a creator's success within his or her chosen domain of achievement?

Before I answer this question directly, let me first acknowledge an undeniable fact: Some predictors of individual achievement or eminence are orthogonal to the variables that correspond with a discipline's hierarchical position. For instance, regardless of domain, every high achiever must possess an exceptional degree of motivation, determination, or persistence (e.g., Cox, 1926; Duckworth, Peterson, Matthews, \& Kelly, 2007; Helmreich, Spence, Beane, Lucker, \& Matthews, 1980; Matthews, Helmreich, Beane, \& Lucker, 1980). In this respect, a Nobel laureate in physics will not differ substantially from a laureate in literature. Complicating matters all the 
more, some predictors of domain affiliation are definitely not predictors of individual success within the chosen domain. For example, the personality variables that correlate with whether or not one becomes a scientist are not identical to the personality variables that correlate with the magnitude of creativity that a scientist exhibits (Feist, 1998; see also Simonton, 2008b).

That said, it remains the case that a subset of the dispositional and developmental factors that predict an individual's domain of achievement is also germane to predicting the same individual's degree of achievement within the domain. In theory, this dual relevance can function three different ways.

First, the most successful, high-impact creators may be those whose dispositional traits and developmental experiences are the most typical of creators in their selected discipline. In more technical terms, we can hypothesize that an individual's impact correlates with his or her dispositional and developmental proximity to the disciplinary centroid (i.e., the "center of mass" for the set of variables defining the underlying dimension; see Abdi, 2007). Hence, a Nobel laureate in chemistry will have characteristics that place him or her right in the middle of the distribution for chemists in general. In contrast, those whose dispositional and developmental attributes place them at the periphery of the distribution will prove less influential, regardless of whether they are higher or lower in the hierarchy. We can style this possibility the domaintypical creator hypothesis.

Second, the most eminent or influential creators may be those whose dispositional traits and developmental experiences are the most typical of creators in a domain one or more steps higher in the hierarchy. Thus, a highly influential psychologist might score on relevant variables in a fashion more typical of biology or even chemistry than of psychology. Persons with an exact-science orientation will do better in a soft science than will those with a soft-science 
orientation. This might be called the domain-progressive creator hypothesis. So-called "physics envy" is not necessarily a bad thing for any nonphysicist.

Third and last, the most illustrious or high-impact creators may be those with dispositional traits and developmental experiences that put them closer to the centroid for a domain lower in the hierarchy. Expressed differently, the most creative practitioners must undergo some degree of regression from the logical, objective, conventional, and formal to the intuitive, subjective, individualistic, and emotional. This may be identified as the domainregressive creator hypothesis. In a way, the same principle that distinguishes revolutionary from normal scientists also distinguishes highly creative from less creative scientists operating within a given domain during its paradigmatic phases. To the extent that revolutionary scientists are often deemed more creative than normal scientists, these assertions can be taken as almost equivalent.

This third hypothesis has the advantage that it appears most consistent with the introspective reports of Nobel-prize winning scientists about their own creative process. To illustrate, Max Planck (1949) noted that creative scientists "must have a vivid intuitive imagination, for new ideas are not generated by deduction, but by an artistically creative imagination" (p. 109). Likewise, Albert Einstein reported that "to these elementary laws there leads no logical path, but only intuition, supported by being sympathetically in touch with experience" (as cited in Holton, 1971-1972, p. 97). These two quotes imply that the best scientific creators are those who are artistically creative rather than those who rely heavily on deliberate and deductive logic.

So which of these three alternatives is the most correct? Even if any conclusion must be considered provisional at this point in our knowledge, I believe that the published data lend the 
most support to the hypothesis of the domain-regressive creator. That is, the major figures in a given domain are more similar to creators who would be considered more typical of a domain lower in the disciplinary hierarchy. In addition, the higher the degree of observed creativity, the lower the placement of the most closely matching discipline. At least this trend can be clearly seen in the research on the dispositional predictors of creativity, which we will look at first. Afterward, I will report the somewhat less tidy findings with regard to the developmental predictors.

\section{Dispositional Predictors}

If the domain-regressive hypothesis is correct, then highly creative scientists should have certain dispositional affinities with creative artists rather than with their less creative scientific colleagues. This expectation appears to be confirmed in self-descriptions (Van Zelst \& Kerr, 1954). In comparison with their less productive colleagues, highly productive scientists describe themselves as more original, less conventional, more impulsive, less inhibited, less formal, and more subjective. These attributes are strongly associated with artistic domains of creative achievement (see, e.g., Feist, 1998).

I might also cite another relevant finding concerning integrative complexity, the factor that discriminates eminent human-science-oriented psychologists from equally eminent naturalscience-oriented psychologists (Suedfeld, 1985). Feist (1994) found that integrative complexity was positively associated with peer-rated eminence for natural scientists, as were total citations received in the professional literature. Critically, it was only the integrative complexity displayed when the scientists spoke about their research that was predictive. The integrative complexity associated to their talks on teaching had, if anything, a negative relationship, as judged by total 
works cited. Although Feist's results had some complexities that cannot be fully accommodated in the current hierarchical model, these specific findings remain suggestive.

But perhaps the best dispositional evidence concerns the inclination toward psychopathology. Earlier, I mentioned Ludwig's (1998) fractal conception of the relationship between mental illness and achievement domain. Now it becomes appropriate to cite Ludwig's (1995) earlier finding that achieved eminence is positively associated with psychological "unease." Extraordinary achievers are seldom easygoing, well-adjusted people who are easily content with their accomplishments or circumstances. Instead they seem to have driven some "Faustian bargain" that never lets them rest (see also Gardner, 1993).

This association becomes more explicitly linked with psychopathology in the research on the psychoticism scale of the Eysenck Personality Questionnaire (Eysenck, 1993, 1995). Individuals who score higher than normal on psychoticism tend to be aggressive, cold, egocentric, impersonal, impulsive, antisocial, unempathetic, and tough-minded. The extreme end of this scale is linked with overt psychopathology. Not surprisingly, therefore, the level of psychoticism corresponds in the expected manner with domain of achievement. Although both scientists and artists score higher than average on this scale, the artists score even higher than the scientists (Feist, 1998). Moreover, there exists some empirical evidence that scores on psychoticism from individuals within a given science or art tend to be positively correlated with productivity, impact, or eminence (Götz \& Götz, 1979; Rushton, 1990). An analogous effect has been found for the clinical scales of the Minnesota Multiphasic Personality Inventory (Barron, 1963). Creative writers score higher than normal, and highly eminent creative writers score higher than the less eminent. 
Eysenck $(1993,1995)$ maintained that the connection between psychoticism and creativity was partially founded on psychoticism's association with reduced latent inhibition. High scorers are less able to filter out supposedly extraneous information. Subsequent researchers have also shown that such defocused attention is correlated with (a) higher openness to experience (Peterson, \& Carson, 2000; Peterson, Smith, \& Carson, 2002), a variable shown to be positively associated with divergent thinking and psychometrically assessed creativity (Harris, 2004; McCrae, 1987), and with (b) objective creative achievement as gauged by actual behaviors (Carson, Peterson, \& Higgins, 2003). Psychoticism, reduced latent inhibition, openness, divergent thinking, and creativity form an intercorrelated cluster of variables (see also Ansburg \& Hill, 2003). Although this cluster is largely uncorrelated with general intelligence (Harris, 2004; see also Eysenck, 1994), high intelligence may play a role in preventing the pathological aspects of psychoticism from interfering with creativity (Carson et al., 2003).

Admittedly, it would require many more empirical investigations before we could draw firm conclusions. Nonetheless, the available research does suggest that the domain-regressive creator hypothesis has the best support. The greatest creators within a domain have dispositional characteristics that move them closer to the mass of creators operating lower down in the disciplinary hierarchy.

\section{Developmental Predictors}

I should begin this section by observing the outcome of an investigation that specifically tested the domain-typical creator hypothesis using developmental variables (Simonton, 1986). The sample consisted of 314 eminent personalities in a diversity of achievement domains, including virtually all major areas of creative achievement. In addition, the subjects were assessed on a very large number of developmental variables, including family and educational 
factors. After first identifying the developmental predictors of an individual's domain affiliation, a domain-typical score was calculated and then correlated with a highly reliable composite measure of eminence $(\alpha=.76)$. The association was virtually zero (multiple regression $\beta=.02$ ). The most eminent members of the sample were no more or less typical of their domain than were their less eminent associates. Hence, it would seem that the only plausible options are the domain-progressive and domain-regressive creator hypotheses.

The weight of the evidence accumulated so far on developmental predictors would seem to endorse the latter hypothesis, but in a manner more tentative and indirect than that seen for dispositional predictors. As a case in point, if one can assume that revolutionary scientists are on average more illustrious than normal scientists, then the same developmental variables associated with belonging in the former rather than the latter group should also predict eminence in a paradigmatic science. Even so, I know of no direct empirical support for this assumption, however plausible it might seem to be. Even worse, some empirical findings seem to contradict the domain-regressive hypothesis. As an example, although laterborns are more likely to be revolutionaries, as expressed in Sulloway's (1996) model, one study of psychologists found that firstborns had a bigger domain-specific impact, at least as assessed by citation counts (Helmreich et al., 1980).

Sulloway (1996) has provided a potential solution to such discrepancies. Although laterborns are most likely to participate in the initial phases of a revolutionary movement, firstborns may be more prone to take over the movement when it begins to exert dominance. In other words, firstborns are more adept at co-opting innovations and making them their own. It takes one kind of person to rebel against authority, another to establish a new authority. Accordingly, the predictive connection between ordinal position and individual eminence may 
depend very much on the domain's status in historical evolution. When a paradigm is well entrenched, firstborns may have the advantage, but the laterborns may come into the fore when the paradigm breaks down during and is replaced by a new paradigm, only to have the firstborns reappear when the revolt converts to the status quo. Clearly, the developmental basis for individual disciplinary eminence may be more finely nuanced than I have envisioned in the hierarchical model.

\section{CONCLUSION}

In this article, I have put forward three interconnected arguments. The first is that that the diverse domains of creative achievement can be arrayed as a hierarchy. This argument was founded on earlier work establishing a hierarchy for major scientific disciplines. That hierarchy was then extrapolated to include the humanities and the arts and interpolated to deal with withindomain variation. The underlying assumption of the hierarchical arrangement is that domainspecific creativity varies from the logical, objective, formal, and conventional to the intuitive, subjective, emotional, and individualistic. I should probably admit that the assertion that the former disciplines reside at the top and the latter rest at the bottom is totally arbitrary. An artist might reasonably decide to invert the hierarchy, placing poetry at the apex and physics at the base. Indeed, this inversion might be justified if we wish to use originality of creative thought as the primary criterion, a point that I will return to in a moment.

The second argument is that a set of dispositional traits and developmental experiences underlie this hierarchical ordering. That is, the hierarchy has a psychological basis. These dispositional and developmental variables influence an individual's preferred form of creative expression - their particular combination of these variables (logical vs. intuitive, objective vs. subjective, formal vs. emotional, conventional vs. individualistic). At one extreme is the 
creativity that characterizes a "tough-minded" science like experimental physics, and at the other extreme is the creativity seen in a "tender-minded" art like romantic poetry.

The third and final argument concerns whether the same dispositional and developmental factors participate in deciding a creator's impact on his or her chosen domain of achievement. After specifying three alternatives - the domain-progressive, domain-typical, or domainregressive creator-I then reviewed the available literature. The empirical research lent the most support to the concept of the domain-regressive creator, although this endorsement was stronger for dispositional than for developmental variables. Nonetheless, the domain-regressive creator hypothesis has the advantage that it is the most consistent with the idea that domains lower in the hierarchy place more emphasis on unrestrained creativity than do domains higher in the ordering. The regression toward a form of creative thought more typical of a lower domain actually constitutes an increase in the level of individual creativity. This increment then contributes to that creator's greater domain-specific impact. As Einstein and Planck observed, even a physicist must occasionally think like a painter or poet to get some really original ideas.

This last claim receives corroboration from research on the avocational activities of eminent scientists (Root-Bernstein, Bernstein, \& Garnier, 1995). High-impact scientists were directly involved in such hobbies as painting, drawing, photography, sculpting, crafts, poetry, and singing. Furthermore, these interests were correlated with diverse modes of thinking that the scientists believed contributed to their creative process. Hence, successful scientists not only have more nonscientific activities than their less successful colleagues, but those activities also appear to be more integrated with their research. It should be immediately apparent that these rich avocational interests are also concordant with what I noted earlier about the relation between creativity and openness to experience. This association means that highly creative persons should 
have extremely wide interests (see also Gough, 1979). These are not narrow-minded persons who concentrate all their waking hours on a highly specialized endeavor.

Naturally, the domain-regressive creator hypothesis, if further confirmed, raises another question: Why do some creative individuals aspire to contribute to a domain that is more logical, objective, conventional, and formal than their own personal inclination? The most obvious answer is that the choice of achievement domain is determined by a great many more variables than just those relevant to hierarchical placement and creative performance. Examples include special ability patterns and vocational interests (see, e.g., Achter, Lubinski, Benbow, \& Eftekhari-Sanjani, 1999; Lubinski \& Benbow, 2006; Park, Lubinski, \& Benbow, 2007). Because these additional factors are differentially dependent on diverse genetic and environmental influences, they may operate in a manner largely orthogonal to the dispositional and developmental variables emphasized in the hierarchical model. As a consequence, each discipline in the hypothesized hierarchy will recruit a mix of domain-progressive, domaintypical, and domain-regressive creators. The domain-typical creators will likely constitute the vast majority, but the domain-regressive creators may represent a highly influential creative minority. To speculate more, perhaps the domain-progressive minority may consist of those who strive to push their domain up the hierarchy. In psychological science, for instance, these individuals might be researchers active in evolutionary psychology, behavior genetics, or the cognitive neurosciences - the three specialties with the most obvious connections with biology.

Even if this article cannot be said to have settled the matter in a conclusive fashion, I hope that will help inspire an agenda for future research. Creativity comes in many varieties, varieties that can be ordered along some hierarchical dimension that has a psychological foundation in terms of disposition and development. Moreover, a creator's success in a chosen 
domain partly depends on the fit between this dimension and the person's dispositional and developmental characteristics. What remains is to fill in the many details and designate the most crucial qualifications.

The tentativeness of the model leads me to raise one last problem. As the domainregressive creator hypothesis has it, the most influential contributors to a specific discipline are those whose dispositional and developmental attributes would normally assign them to a lower level in the disciplinary hierarchy. The highly creative are apparently interlopers, venturing into domains where they may not really belong. Yet where does that leave a creator who is already operating at the bottom level of the hierarchy — the domain that is already the maximally intuitive, subjective, emotional, and individualistic? More specifically, into what domain does the emotive poet regress? Perhaps it is no mere coincidence that such poets have the highest rates of incapacitating mental illness, suicide, and substance abuse (Kaufman, 2000-2001; Ludwig, 1995; Martindale, 1972; cf. Post, 1996). There is no variety of creativity to which they can descend, only madness. The poet's creativity must invariably operate at the very edge of sanity. On the other side of that thin line dwells the almost autistic reductio ad absurdum of extreme intuition, subjectivity, emotionality, and individualism.

Acknowledgments - This article was based on an invited address delivered at the Bi-Annual Conference of the International Society for the Psychology of Science and Technology, Humboldt-Universität, Berlin.

\section{REFERENCES}


Abdi, H. (2007). Centroid. In N.J. Salkind (Ed.), Encyclopedia of measurement and statistics (Vol. 1, pp. 128-129). Thousand Oaks, CA: Sage.

Achter, J.A., Lubinski, D., Benbow, C.P., \& Eftekhari-Sanjani, H. (1999). Assessing vocational preferences among gifted adolescents adds incremental validity to abilities: A discriminant analysis of educational outcomes over a 10-year interval. Journal of Educational Psychology, 91, 777-786.

Altus, W.D. (1966). Birth order and its sequelae. Science, 151, 44-48.

Ansburg, P.I., \& Hill, K. (2003). Creative and analytic thinkers differ in their use of attentional resources. Personality and Individual Differences, 34, 1141-1152.

Barron, F.X. (1963). Creativity and psychological health: Origins of personal vitality and creative freedom. Princeton, NJ: Van Nostrand.

Berry, C. (1981). The Nobel scientists and the origins of scientific achievement. British Journal of Sociology, 32, 381-391.

Bliss, W.D. (1970). Birth order of creative writers. Journal of Individual Psychology, 26, 200202.

Carson, S., Peterson, J.B., \& Higgins, D.M. (2003). Decreased latent inhibition is associated with increased creative achievement in high-functioning individuals. Journal of Personality and Social Psychology, 85, 499-506.

Cattell, R.B., \& Drevdahl, J.E. (1955). A comparison of the personality profile (16 P. F.) of eminent researchers with that of eminent teachers and administrators, and of the general population. British Journal of Psychology, 46, 248-261.

Chambers, J.A. (1964). Relating personality and biographical factors to scientific creativity. Psychological Monographs: General and Applied, 78(7, Whole No. 584). 
Clark, R.D., \& Rice, G.A. (1982). Family constellations and eminence: The birth orders of Nobel Prize winners. Journal of Psychology, 110, 281-287.

Cleveland, W.S. (1984). Graphs in scientific publications. American Statistician, 38, 261-269.

Coan, R.W. (1968). Dimensions of psychological theory. American Psychologist, 23, 715-722.

Coan, R.W. (1979). Psychologists: Personal and theoretical pathways. New York: Irvington.

Cole, S. (1983). The hierarchy of the sciences? American Journal of Sociology, 89, 111-139.

Comte, A. (1855). The positive philosophy of Auguste Comte (H. Martineau, Trans.). New York: Blanchard. (Original work published 1839-1842)

Cox, C. (1926). The early mental traits of three hundred geniuses. Stanford, CA: Stanford University Press.

Cronbach, L.J. (1957). The two disciplines of scientific psychology. American Psychologist, 12, $671-684$.

de Candolle, A. (1873). Histoire des sciences et des savants depuis deux siècles[A history of sciences and scientists for the last 200 years]. Geneva, Switzerland: Georg.

Duckworth, A.L., Peterson, C., Matthews, M.D., \& Kelly, D.R. (2007). GRIT: Perseverance and passion for long-term goals. Journal of Personality and Social Psychology, 92, 10871101.

Eiduson, B.T. (1962). Scientists: Their psychological world. New York: Basic Books.

Eysenck, H.J. (1993). Creativity and personality: Suggestions for a theory. Psychological Inquiry, 4, 147-178.

Eysenck, H.J. (1994). Creativity and personality: Word association, origence, and psychoticism. Creativity Research Journal, 7, 209-216. 
Eysenck, H.J. (1995). Genius: The natural history of creativity. Cambridge, England: Cambridge University Press.

Feist, G.J. (1994). Personality and working style predictors of integrative complexity: A study of scientists' thinking about research and teaching. Journal of Personality and Social Psychology, 67, 474-484.

Feist, G.J. (1998). A meta-analysis of personality in scientific and artistic creativity. Personality and Social Psychology Review, 2, 290-309.

Feist, G.J. (2006). How development and personality influence scientific thought, interest, and achievement. Review of General Psychology, 10, 163-182.

Galton, F. (1874). English men of science: Their nature and nurture. London: Macmillan.

Gardner, H. (1993). Creating minds: An anatomy of creativity seen through the lives of Freud, Einstein, Picasso, Stravinsky, Eliot, Graham, and Gandhi. New York: Basic Books.

Gholson, B., \& Barker, P. (1985). Kuhn, Lakatos, and Laudan: Applications to the history of physics and psychology. American Psychologist, 40, 755-769.

Götz, K.O., \& Götz, K. (1979). Personality characteristics of successful artists. Perceptual and Motor Skills, 49, 919-924.

Gough, H.G. (1979). A creative personality scale for the adjective check list. Journal of Personality and Social Psychology, 37, 1398-1405.

Hagstrom, W.O. (1974). Competition in science. American Sociological Review, 39, 1-18.

Harris, J.A. (2004). Measured intelligence, achievement, openness to experience, and creativity. Personality and Individual Differences, 36, 913-929.

Hedges, L.V. (1987). How hard is hard science, how soft is soft science? American Psychologist, 42, 443-455. 
Helmreich, R.L., Spence, J.T., Beane, W.E., Lucker, G.W., \& Matthews, K.A. (1980). Making it in academic psychology: Demographic and personality correlates of attainment. Journal of Personality and Social Psychology, 39, 896-908.

Holton, G. (1971-1972). On trying to understand the scientific genius. American Scholar, 41, $95-110$.

Jamison, K.R. (1989). Mood disorders and patterns of creativity in British writers and artists. Psychiatry, 52, 125-134.

Johnson, J.A., Germer, C.K., Efran, J.S., \& Overton, W.F. (1988). Personality as the basis for theoretical predilections. Journal of Personality and Social Psychology, 55, 824-835.

Kaufman, J. C. (2000-2001). Genius, lunatics and poets: Mental illness in prize-winning authors. Imagination, Cognition \& Personality, 20, 305-314.

Kimble, G.A. (1984). Psychology's two cultures. American Psychologist, 39, 833-839.

Kuhn, T.S. (1970). The structure of scientific revolutions (2nd ed.). Chicago: University of Chicago Press.

Lubinski, D., \& Benbow, C.P. (2006). Study of mathematically precocious youth after 35 years: Uncovering antecedents for the development of math-science expertise. Perspectives on Psychological Science, 1, 316-345.

Ludwig, A.M. (1992). Creative achievement and psychopathology: Comparison among professions. American Journal of Psychotherapy, 46, 330-356.

Ludwig, A.M. (1995). The price of greatness: Resolving the creativity and madness controversy. New York: Guilford Press.

Ludwig, A.M. (1998). Method and madness in the arts and sciences. Creativity Research Journal, 11, 93-101. 
Manniche, E., \& Falk, G. (1957). Age and the Nobel prize. Behavioral Science, 2, 301-307.

Martindale, C. (1972). Father absence, psychopathology, and poetic eminence. Psychological Reports, 31, 843-847.

Matthews, K.A., Helmreich, R.L., Beane, W.E., \& Lucker, G.W. (1980). Pattern A, achievement striving, and scientific merit: Does Pattern A help or hinder? Journal of Personality and Social Psychology, 39, 962-967.

McCrae, R.R. (1987). Creativity, divergent thinking, and openness to experience. Journal of Personality and Social Psychology, 52, 1258-1265.

McDowell, J.M. (1982). Obsolescence of knowledge and career publication profiles: Some evidence of differences among fields in costs of interrupted careers. American Economic Review, 72, 752-768.

Park, G., Lubinski, D., \& Benbow, C.P. (2007). Contrasting intellectual patterns predict creativity in the arts and sciences: Tracking intellectually precocious youth over 25 years. Psychological Science, 18, 948-952.

Peterson, J.B., \& Carson, S. (2000). Latent inhibition and openness to experience in a highachieving student population. Personality and Individual Differences, 28, 323-332.

Peterson, J.B., Smith, K.W., \& Carson, S. (2002). Openness and extraversion are associated with reduced latent inhibition: Replication and commentary. Personality and Individual Differences, 33, 1137-1147.

Planck, M. (1949). Scientific autobiography and other papers (F. Gaynor, Trans.). New York: Philosophical Library.

Post, F. (1994). Creativity and psychopathology: A study of 291 world-famous men. British Journal of Psychiatry, 165, 22-34. 
Post, F. (1996). Verbal creativity, depression and alcoholism: An investigation of one hundred American and British writers. British Journal of Psychiatry, 168, 545-555.

Raskin, E.A. (1936). Comparison of scientific and literary ability: A biographical study of eminent scientists and men of letters of the nineteenth century. Journal of Abnormal and Social Psychology, 31, 20-35.

Roe, A. (1953). The making of a scientist. New York: Dodd, Mead.

Roeckelein, J.E. (1996). Citation of laws and theories in textbooks across 112 years of psychology. Psychological Reports, 79, 979-998.

Roeckelein, J.E. (1997). Psychology among the sciences: Comparisons of numbers of theories and laws cited in textbooks. Psychological Reports, 80, 131-141.

Root-Bernstein, R.S., Bernstein, M., \& Garnier, H. (1995). Correlations between avocations, scientific style, work habits, and professional impact of scientists. Creativity Research Journal, 8, 115-137.

Rosenthal, R. (1990). How are we doing in soft psychology? American Psychologist, 45, 775777.

Rushton, J.P. (1990). Creativity, intelligence, and psychoticism. Personality and Individual Differences, 11, 1291-1298.

Schachter, S. (1963). Birth order, eminence, and higher education. American Sociological Review, 28, 757-768.

Schachter, S., Christenfeld, N., Ravina, B., \& Bilous, F. (1991). Speech disfluency and the structure of knowledge. Journal of Personality and Social Psychology, 60, 362-367.

Schaefer, C.E., \& Anastasi, A. (1968). A biographical inventory for identifying creativity in adolescent boys. Journal of Applied Psychology, 58, 42-48. 
Schubert, D.S.P., Wagner, M.E., \& Schubert, H.J. P. (1977). Family constellation and creativity: Firstborn predominance among classical music composers. Journal of Psychology, 95, $147-149$.

Simonton, D.K. (1975). Sociocultural context of individual creativity: A transhistorical timeseries analysis. Journal of Personality and Social Psychology, 32, 1119-1133.

Simonton, D.K. (1984). Artistic creativity and interpersonal relationships across and within generations. Journal of Personality and Social Psychology, 46, 1273-1286.

Simonton, D.K. (1986). Biographical typicality, eminence, and achievement style. Journal of Creative Behavior, 20, 14-22.

Simonton, D.K. (1987). Developmental antecedents of achieved eminence. Annals of Child Development, 5, 131-169.

Simonton, D.K. (1992a). Leaders of American psychology, 1879-1967: Career development, creative output, and professional achievement. Journal of Personality and Social Psychology, 62, 5-17.

Simonton, D.K. (1992b). The social context of career success and course for 2,026 scientists and inventors. Personality and Social Psychology Bulletin, 18, 452-463.

Simonton, D.K. (1997). Foreign influence and national achievement: The impact of open milieus on Japanese civilization. Journal of Personality and Social Psychology, 72, 86-94.

Simonton, D.K. (2000). Methodological and theoretical orientation and the long-term disciplinary impact of 54 eminent psychologists. Review of General Psychology, 4, 1-13.

Simonton, D.K. (2002). Great psychologists and their times: Scientific insights into psychology's history. Washington, DC: American Psychological Association. 
Simonton, D.K. (2004). Psychology's status as a scientific discipline: Its empirical placement within an implicit hierarchy of the sciences. Review of General Psychology, 8, 59-67.

Simonton, D.K. (2007). Creativity: Specialized expertise or general cognitive processes? In M.J. Roberts (Ed.), Integrating the mind: Domain general versus domain specific processes in higher cognition (pp. 351-367). Hove, United Kingdom: Psychology Press.

Simonton, D.K. (2008a). Gender differences in birth order and family size among 186 eminent psychologists. Journal of Psychology of Science and Technology, 1, 15-22.

Simonton, D.K. (2008b). Scientific talent, training, and performance: Intellect, personality, and genetic endowment. Review of General Psychology, 12, 28-46.

Smith, L.D., Best, L.A., Stubbs, D.A., Johnston, J., \& Archibald, A.B. (2000). Scientific graphs and the hierarchy of the sciences. Social Studies of Science, 30, 73-94.

Stephan, P.E., \& Levin, S.G. (1993). Age and the Nobel Prize revisited. Scientometrics, 28, $387-$ 399.

Sternberg, R.J. (2005). The domain generality versus specificity debate: How should it be posed? In J.C. Kaufman \& J. Baer (Eds.), Faces of the muse: How people think, work, and act creatively in diverse domains (pp. 299-306). Mahwah, NJ: Erlbaum.

Suedfeld, P. (1985). APA presidential addresses: The relation of integrative complexity to historical, professional, and personal factors. Journal of Personality and Social Psychology, 47, 848-852.

Sulloway, F.J. (1996). Born to rebel: Birth order, family dynamics, and creative lives. New York: Pantheon.

Suls, J., \& Fletcher, B. (1983). Social comparison in the social and physical sciences: An archival study. Journal of Personality and Social Psychology, 44, 575-580. 
Terman, L.M. (1954). Scientists and nonscientists in a group of 800 gifted men. Psychological Monographs: General and Applied, 68(7, Whole No. 378), 1-44.

Terry, W.S. (1989). Birth order and prominence in the history of psychology. Psychological Record, 39, 333-337.

Van Zelst, R.H., \& Kerr, W.A. (1954). Personality self-assessment of scientific and technical personnel. Journal of Applied Psychology, 38, 145-147.

Fig. 1. The disciplines of physics, chemistry, biology, psychology, and sociology placed in a Comtean hierarchy of the sciences. The horizontal axis indicates the rank and the vertical axis indicates the composite score on the seven primary indicators (i.e., citation concentration, early impact rate, peer evaluation consensus, obsolescence rate, graph prominence, consultation rate, and the discipline's theories-to-laws ratio). Taken from Simonton (2004). 